\title{
Some Further Aids for the Handicapped Leprosy Patient ${ }^{*}$
}

\author{
W. H. JENNINGS \\ S.R.S. Action-Research Project, \\ The Dr Bandorawalla Leprosy Hospital, Kondhwa, Poona, India
}

\begin{abstract}
On the basis of his practical experience in the field the author describes four ingenious and, in respect of three of the $m$, inexpensive appliances which have been devised primarily for the use of handicapped leprosy patients-but which could be equally useful to persons disabled from other causes-to enable them to carry on a useful and gainful occupation.
\end{abstract}

\section{Introduction}

Some of the common deformities of leprosy patients are also seen in other conditions such as the ulnar-nerve damage of industrial injury, or the unshapely and stiff hands of sufferers from rheumatoid arthritis.

I consider that "experienced" social workers are often unnecessarily concerned about the "stigma" of special tools and appliances, which they would otherwise recommend. A handle may be "too bulky" and a tool so "unconventional" that the user will "at once be recognized" as suffering from leprosy the moment he uses it outside the institution. I would assert that anything that makes work easier is acceptable, and is usually accepted. Aids for those suffering from deformities caused by leprosy could also be used to help people disabled by other causes, and furthermore, if any of them can be of help to normal people to work more easily or rapidly, then their acceptance is more assured.

The Action-Research Project at the Dr Bandorawalla Leprosy Hospital, Kondhwa, Poona has, as one of its objectives, the experimental social rehabilitation of ex-leprosy patients after vocational training. Carpentry, tailoring, cane-work, sheep breeding, and poultry farming are some of the vocations patients learn under this project before their discharge. A high proportion of these patients have irremediable handicaps. Working for this project, I have had the opportunity of devising, and experimenting with, aids for such patients.

\section{New Aids}

Four new aids specially devised for handicapped leprosy patients are described below.

1. THE "KONDHWA" CLOTH-CUTTER (Fig. 1)

This is constructed by mounting a pair of cloth-cutting scissors on a wooden table. One of its blades is rigidly fixed to the table while the other

* Received for publication 20 September, 1972. 


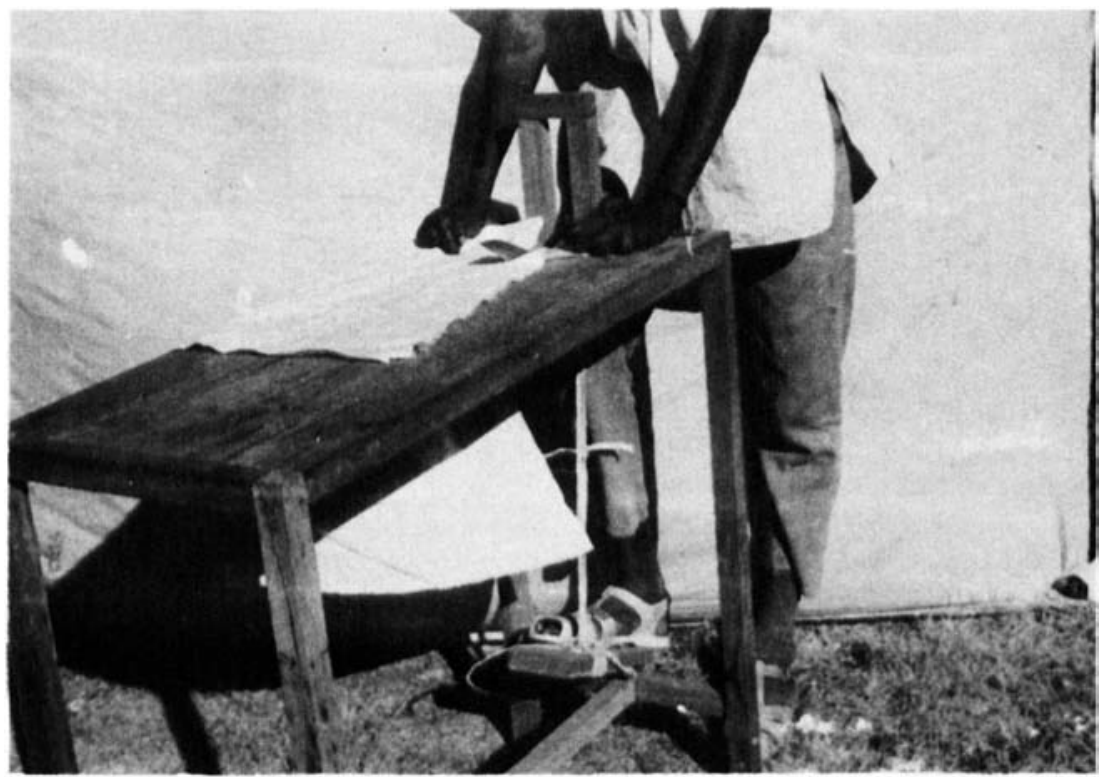

Fig. 1. Unable to use his badly damaged hands for cutting cloth, a patient makes use of the "Kondhwa" cloth-cutter.

is mobile and operated by a foot-pedal and spring. It is useful for patients who lack digits or range of the thumb web necessary for the efficient use of scissors in cutting cloth. Including labour cost, this could be made for less than 70 rupees by using materials of moderate quality. Our disabled patients, when leaving the hospital after a course in tailoring, are given a cloth-cutter if they need one as part of the equipment for setting up in business in their home.

\section{SEWING-MACHINE PEDAL SPRING (Fig. 2)}

This device helps amputees and those who can use only one foot for operating a sewing-machine. The spring lifts the pedal up when the downward foot pressure is released, thus compensating for the action of the other foot. Any type of spring may be used provided it is coiled, between 8 and 12 in $(20$ to $30 \mathrm{~cm})$ long, and not too powerful.

\section{KNIFE AND BLOCK COMBINATION (Figs. 3-5)}

A discarded surgical blade attached to a smoothened wooden handle enables deformed hands to slit hems conveniently when the cloth is held over a wooden block attached to the side of the sewing-machine board. This also protects anaesthetic hands. (Tailors in India slit hems usually by folding the cloth tightly over the index finger of one hand while using a bare razor blade held by the other hand.)

\section{THE "KONDHWA" CANE HOLDER (Fig. 6)}

Cane-craft is a very profitable trade, but is usually not recommended for leprosy patients because of the high risk of damage to the fingers. The holder 


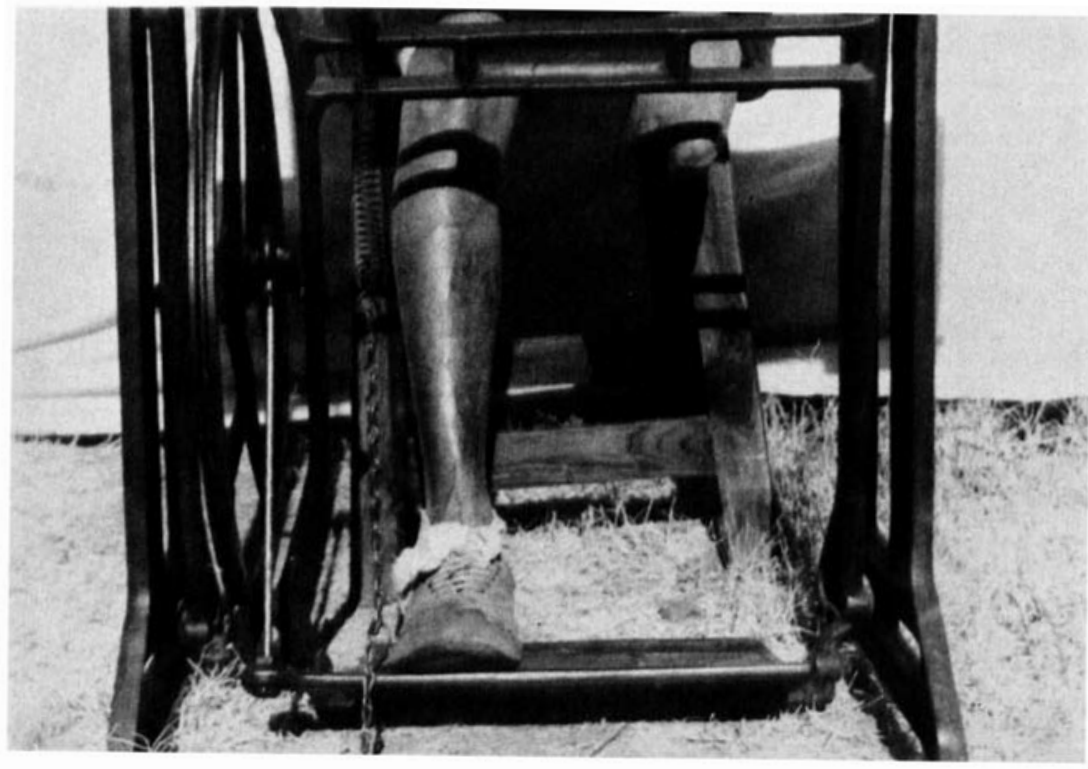

Fig. 2. An amputee operates a sewing-machine by help of the pedal spring.

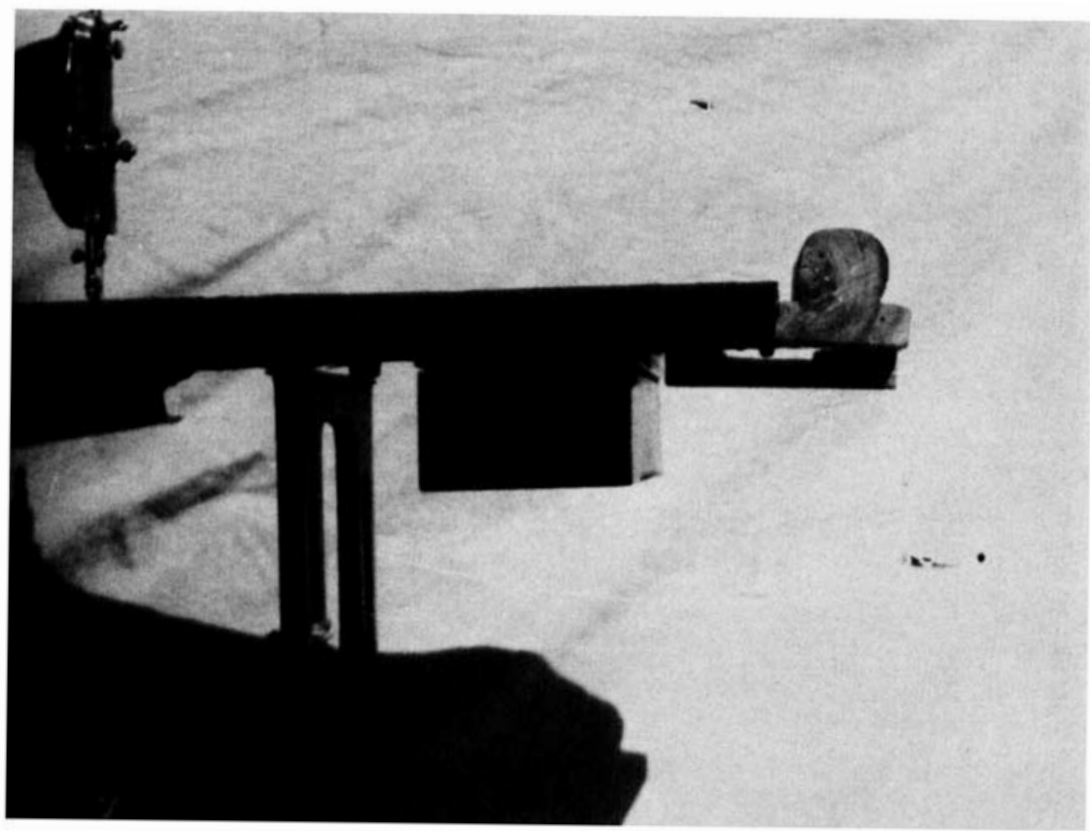

Fig. 3. Sewing-machine with wooden block attached at the side to afford convenience and safety in slitting hems. 


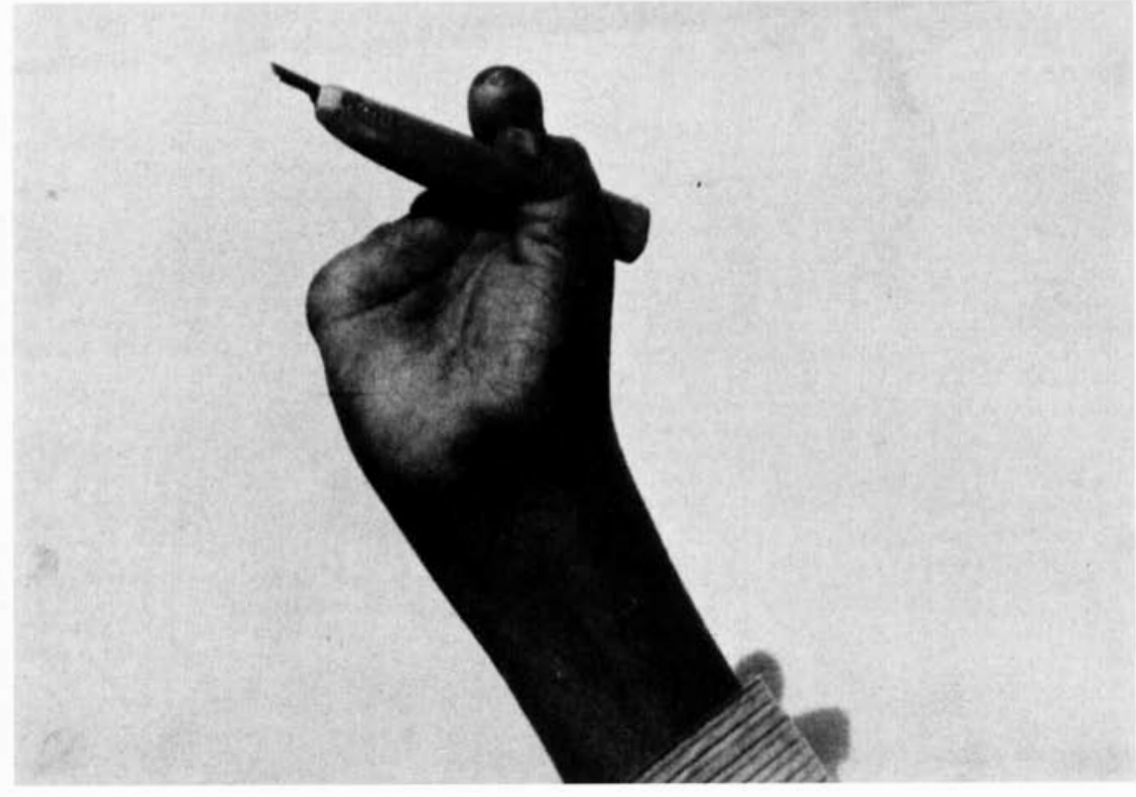

Fig. 4. Devoid of fingers except for two stumps, this hand holds the knife in readiness for use with the block.

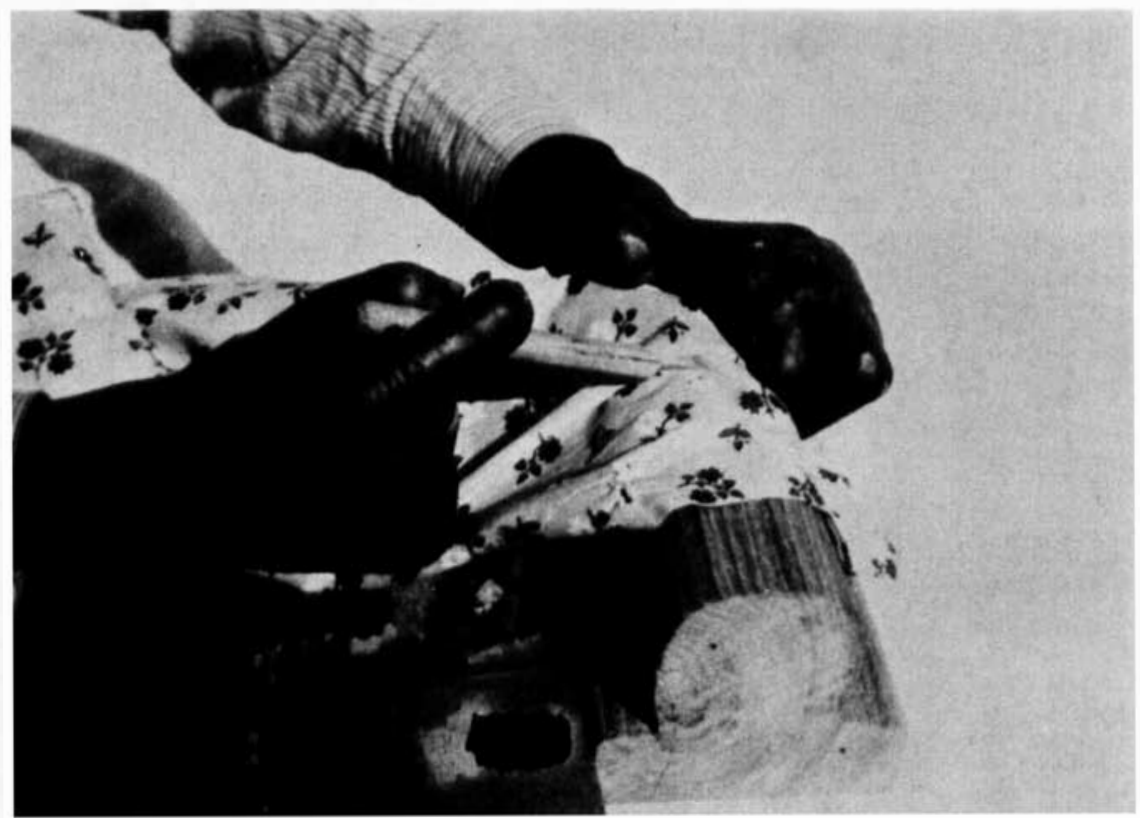

Fig. 5. Using the knife and block, the almost digitless hand slits a hem. 
enables gripping and tightening of the cane to be carried out safely, and can even be used by mobile claw-hands. Cane work is quite safe as long as the cane is not held by the bare hands during work. The holder is made of two blocks of wood, the moulded surface of one block fitting into the grooved surface of the other; both blocks are hinged at one end, from which an arm protrudes from each block (Fig. 6). The grooved and moulded surfaces afford a firm hold of the cane and the protruding arms enable easy opening of the jaws of the holder (Fig. 7).

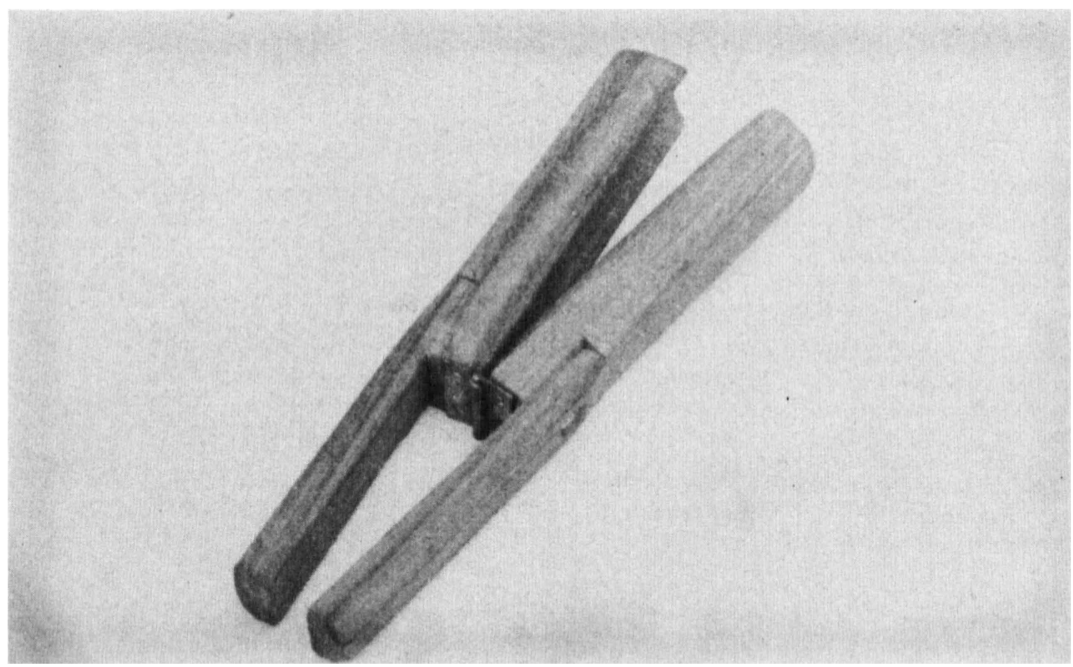

Fig. 6. The "Kondhwa" cane holder.

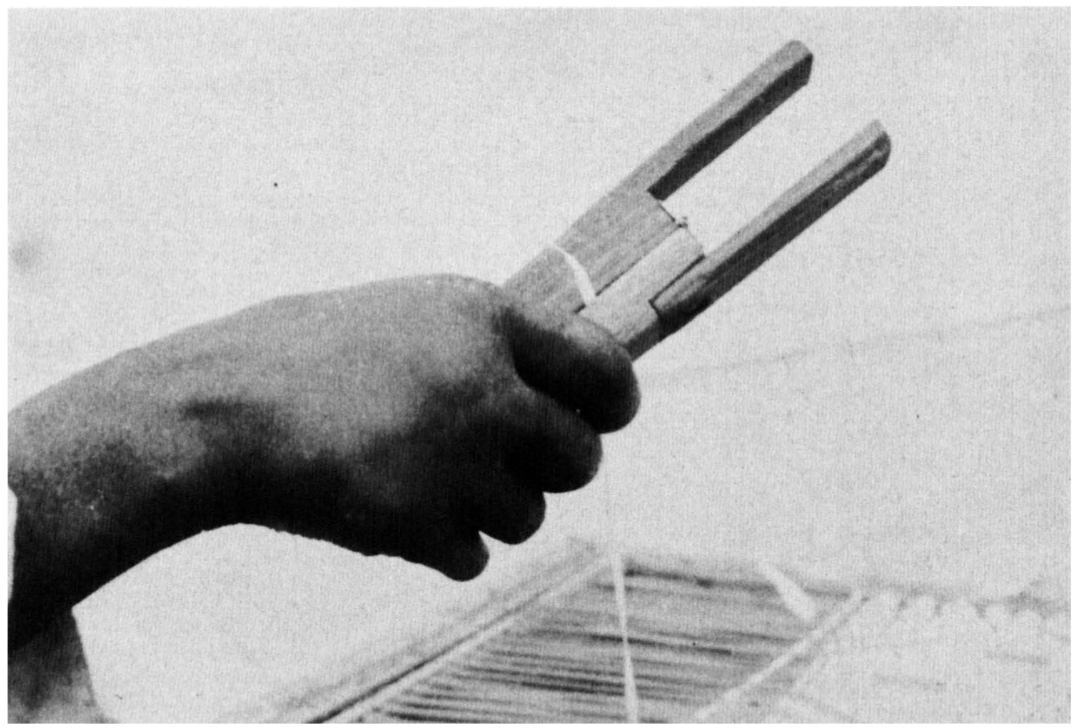

Fig. 7. An anaesthetic hand using the cane holder while working on a cane chair. 


\section{Discussion}

In poor countries where leprosy is prevalent, and where thousands need physical rehabilitation, the main criterion is practicability. Any aids devised therefore should be cheap to make and convenient to use, no matter how crude their appearance.

Excepting the cloth-cutter, all the aids mentioned in this paper could be made for, at most, 5 rupees. The cloth-cutter costs 70 rupees. These aids could be useful also to many persons disabled from other causes than leprosy, and the cane holder and wooden block and knife might appeal even to normal people.

\section{Acknowledgements}

My thanks are due to Dr J. M. Mehta, President, Poona District Leprosy Committee, who is also chief administrator and honorary surgeon to the hospital, and to $\mathrm{Mr} \mathrm{S}$. W. Gokhale, Principal Investigating Officer, SRS Action-Research Project, Poona District Leprosy Committee, for allowing me project materials for constructing these devices, for all their encouragement, and for their permission to publish this paper. 